\title{
Exploring infant feeding practices: cross- sectional surveys of South Western Sydney, Singapore, and Ho Chi Minh City
}

Timothy Yong Qun Leow, Andrew Ung, Shelley Qian, Jessie Thanh Nguyen, Yvonne An, Poonam Mudgil*i(D) and John Whitehall

\begin{abstract}
Background: Infant feeding practices are known to influence the child's long-term health. Studies have associated obesity and other diseases with reduced breastfeeding and early introduction of high calorie beverages (HCBs). The rising prevalence of obesity is already a problem in most developed countries, especially Australia, but cultural differences are influential. Our aim is to examine and compare infant feeding practices and educational levels of respondents through questionnaires in three culturally different sites: Campbelltown (South Western Sydney), Australia, Singapore and Ho Chi Minh City, Vietnam (HCMC).
\end{abstract}

Methods: Consenting parents and carers (aged $\geq 18$ years old) of at least one child ( $\leq 6$ years old) were recruited from paediatric clinics in Campbelltown, Singapore and HCMC. Participants completed an infant feeding practices questionnaire regarding breastfeeding, beverage and solid initiation in addition to the parent's ethnicity, age, and educational level. Data was analysed quantitatively using SPSS.

Results: Two hundred eighty-three participants were recruited across the three sites, HCMC $(n=84)$, Campbelltown $(n=108)$, and Singapore $(n=91) .237$ (82.6\%) children were breastfed but in all only $100(60.2 \%)$ were exclusively breastfed for five months or more. There was a statistical difference in rates of breast feeding between each region. HCMC $(n=18,21.4 \%)$ had the lowest, followed by Campbelltown $(n=35,32.4 \%)$, and then Singapore $(n=47,51.7 \%)$. There was also a difference in rates of introduction of HCBs by 3 years of age, with those in HCMC $(n=71,84.5 \%)$ were higher than Campbelltown $(n=71,65.8 \%)$ and Singapore $(n=48,52.8 \%)$. The educational level of respondents was lower in Vietnam where only $46.4 \%(n=39)$ had completed post-secondary education, compared to $75.0 \%(n=81)$ in Campbelltown and $75.8 \%(n=69)$ in Singapore.

Conclusions: Rates of breast feeding were inversely correlated with rates of introduction of HCB and positively related to educational achievement. Vietnam had lowest rates of breast feeding, higher rates of introduction of HCBs, and lower rates of education. Given rising rates of obesity, there is a need for more effective programmes to promote breast feeding and restrict false advertising of HCBs.

Keywords: Infant feeding, Breast feeding, Paediatric nutrition, Obesity, Australia, Vietnam, Singapore

\footnotetext{
* Correspondence: p.mudgil@westernsydney.edu.au

Department of Paediatrics, School of Medicine, Western Sydney University, Sydney, NSW, Australia
} 


\section{Background}

Appropriate nutrition is fundamental for a child's development. Inappropriate feeding practices, such as a shorter length of breastfeeding and early introduction of solids or high calorie beverages (HCBs), have been associated with dental caries [1], diabetes [2], nutritional deficits and bone catabolism [3], hypertension [4], obesity [5-7], and metabolic syndrome as adults [8].

WHO guidelines [9] recommend exclusive breastfeeding for the first 6 months, introduction of complementary foods at 6 months (but not before 4 months), and concurrent breastfeeding until 24 months or longer [10-12]. Australia, Vietnam and Singapore have similar guidelines $[13,14]$.

Breast milk contains all the required nutrients for growth in the first six months of life [15]. It has been associated with better cognitive development, and the prevention of such negative health outcomes as infections (gastrointestinal and respiratory), obesity, diabetes, cardiovascular disease, and sudden infant death [10, 15-17].

Formula-fed infants gain weight more quickly and have higher BMI at 6 years of age than their breastfed counterparts [18-20]. Reasons include the higher protein content of infant formula and parental desire to ensure the whole bottle is emptied each feed [18]. A faster growth rate is, however, associated with a higher incidence of obesity [20] and, therefore, a delay in solid food introduction until 24 weeks appears to reduce risk of child obesity at 10 years [6].

HCBs contribute to obesity [5, 21, 22]. They include soft drinks, energy drinks and fruit drinks with added sugar [23-25]. Earlier introduction not only provides excess calories in infancy but is known to induce sustained consumption in later years [26], predisposing to obesity and metabolic syndrome $[5,7,27]$. The addition of caffeine to HCBs compounds the problems of obesity with predisposition to hyperactivity and addictive behaviour in children [21, 28-30].

Childhood obesity affects psychological and physical health, including orthopaedic and respiratory problems and the advent of metabolic syndrome [31-33]. In Singapore, in 2012, the rate of clinical childhood obesity was reported to be $11 \%$, but is now increasing $[34,35]$. In 2011-12, some 25\% of Australian children aged 5-17 years were reported to be overweight [36], with $7.6 \%$ being clinically obese [37]. In Vietnam, in 2007-13, the rate of clinical obesity in children $<5$ years old was reported to be between $11.5-16.3 \%$ [38, 39]. Rates of obesity are generally twice as high in countries of greater income [40-42].

As cultural practices influence feeding, we aimed to investigate and compare infant feeding practices at three sites with cultural and demographic differences. Campbelltown in South-Western Sydney (SWS), Singapore and Ho Chi Minh City (HCMC) [43, 44]. SWS, a lower socioeconomic region of Sydney has a culturally diverse population [45] of which about $40 \%$ come from non-English speaking backgrounds. Its birth rate is higher than the Australian average. Singapore [46] is an established "middle-class" state, with an ageing population, predominately Chinese ethnicity and four official languages, English, Mandarin, Tamil, and Malay. HCMC is the largest city in Vietnam [47] a developing economy whose majority is of the Viet (Khin) ethnicity and language.

\section{Methods}

\section{Data collection}

A voluntary, self-reported survey was administered to parents or carers, eighteen years and over, who were responsible for children less than six years old. The participants were approached randomly at the three sites: outpatient clinics and public parks in the vicinity of Campbelltown Hospital, Xom Moi medical centre in HCMC, and Singapore General Hospital. Data collection occurred between December 2014 and February 2015.

Participants were given a participant information sheet and an explanation of the project before the survey was completed. Participants were excluded if they were not fluent in English or Vietnamese; or were illiterate.

\section{The various drinks were defined as below}

Cordial: flavoured syrup that may be mixed with water.

$100 \%$ fruit juice: either self-juiced from fresh fruit or bottled and claimed by manufacturer to contain $100 \%$ natural fruit without additives.

Fruit drink: juice without associated claims to be totally comprised of fruit derivatives.

Non-caffeinated soft-drinks: sweetened carbonated beverages, without caffeine.

Caffeinated soft-drinks: sweetened carbonated beverages, advertised to contain caffeine with an average concentration of $30 \mathrm{mg}$ per $375 \mathrm{ml}$.

Energy drinks: soft-drinks with $\geq 80 \mathrm{mg}$ of caffeine per $375 \mathrm{ml}$ (1 can).

High caloric beverages (HCBs): cordial, flavoured milk, $100 \%$ fruit juice, fruit drink, non-caffeinated and caffeinated soft-drinks, and energy drinks, all containing around $10 \%$ glucose.

Caffeinated drinks (CDs): caffeinated soft-drinks, energy drinks, coffee, and tea.

\section{The infant feeding questionnaire}

The survey consisted of basic demographic questions of the parent or carer including gender, age, level of education, preferred language, place of birth and number of children being cared for. Questions relating to the youngest child's diet included the age to which the child was exclusively breastfed, whether any of the listed drinks had been commenced in the child's diet, at what age they were introduced 
and the frequency of consumption. Questions also included the age of introduction of solid foods, the types of those solid foods and their frequency of consumption (See Additional file 1).

The questionnaire was conducted in English in Australia and Singapore, and Vietnamese in Vietnam. The three cities were selected in part due to convenience sampling. There are also unique demographic qualities which we wanted to compare, culturally - in relation to the infant feeding practices [Ho Chi Minh - a predominantly Eastern culture city in a developing country; Singapore - a mixed Eastern-Western culture in an exBritish colony in a developed country; South-Western Sydney - a predominantly Western culture region in a developed country].

All completed questionnaires were kept confidential and anonymous. This project was approved from the University of Western Sydney Human Research Ethics Committee (HREC H9140, H9067), Liverpool Local Health District for the site at Campbelltown Hospital (HREC/13/ LPOOL/153 and SSA/13/LPOOL/154), Singapore General Hospital (CIRB 2015/2078), and Xom Moi Medical Centre certification.

\section{Statistical analysis}

The data from the survey were entered into SPSS 20 and all statistical analyses were conducted using SPSS. Descriptive statistics of the demographic features for the participants and the youngest child were analysed. Line graphs showing the cumulative frequencies by age for the introduction of different drinks by location were produced. A one-way Analysis of Variance (ANOVA) was performed between location and age of introduction of the various drinks, and location and age of exclusive breastfeeding. Each drink was individually analysed using ANOVA consisting of one independent variable (with three levels: HCMC, Campbelltown, and Singapore) and one dependent variable (the age of introduction of that drink). Post-hoc Tukey HSD analysis was performed on statistically significant $(p<0.05)$ results from the ANOVA test.

\section{Results}

Two hundred eighty-three participants completed the written questionnaire: 108 from Campbelltown, 91 from Singapore, and 84 from HCMC. Of the 283 respondents, $37(12.9 \%)$ were male and $246(87.5 \%)$ were female. The ages of the respondents ranged from 20 to 70 with the majority between 25 to 39 (79.8\%, 226/283). Most respondents had completed tertiary education (59.2\%, 170/ 283). $77.7 \%$ (220/283) of participants cared for 2 or less children (Additional file 2).

The children in the three locations were similar: The median age of the child which was the subject of the questionnaire was 19 months (IQR 25) and gender rates were very similar between sites: 150 (53.0\%) were boys and 133 (47.0\%) girls (Additional file 3).

Overall, $64.4 \%$ of 283 participants began to feed their children exclusively with breast milk, but this number dropped to $41.2 \%$ at four months, and $24.4 \%$ at six months (Fig. 1). In HCMC, 59.5\% of mothers began exclusively breastfeeding but this dropped to $29.0 \%$ at four months, and $14.5 \%$ at six months. In Campbelltown, $61.1 \%$ of mothers began exclusively breastfeeding but this dropped to $39.8 \%$ at four months and $21.3 \%$ at six months. In Singapore, $67.0 \%$ of mothers began exclusively breastfeeding but this rate dropped to $55.0 \%$ at four months and $37.4 \%$ at six months. The duration of exclusive breastfeeding differed significantly between locations, $F(2189)=29.29$, $p<0.005$. A Post-hoc Tukey test showed it was significantly lower in Vietnam than Campbelltown $(p<0.005)$, and in Vietnam compared to Singapore $(p<0.005)$. There was no significant difference between Campbelltown and Singapore.

The percentage of children being introduced solid foods at four months was $21.9 \%$ in Campbelltown, $22.2 \%$ in HCMC, and 9.1\% in Singapore. By six months the percentage of children receiving solid foods was 76.0\% in Campbelltown, 90.1\% in HCMC, and 66.7\% in Singapore (Fig. 2). These rates were not statistically different.

HCBs, such as cordial, flavoured milk, 100\% fruit juice, fruit drink, and non-caffeinated soft drinks (Figs. 3, 4, 5, $6,7,8,9$ and 10), were introduced at an early age in all localities, but more frequently in Vietnam. 36.9\% of respondents in $\mathrm{HCMC}$ reported giving $\mathrm{HCBs}$ to children at six months or less, compared with $13.0 \%$ in Campbelltown and $12.1 \%$ in Singapore. At one year, $72.6 \%$ of participants in HCMC had introduced HCBs, compared to $32.4 \%$ in Campbelltown and $36.3 \%$ in Singapore. By three years of age, $84.5 \%$ of participants in HCMC had introduced HCBs, compared to $65.8 \%$ in Campbelltown and $52.8 \%$ in Singapore. These differences were statistically significant for both age and rate of introductions $p<0.05$. HCMC had introduced more $\mathrm{HCBs}$ and at an earlier age than the other sites at a statistically significant rate to children ( $\leq 3$ years old).

Caffeinated soft drinks (CDs), were introduced at an early age in all localities (Figs. 9, 10, 11, 12 and 13) In HCMC and Campbelltown they were introduced by six months to $4.8 \%$ and $0.9 \%$ of children respectively. By one year of age, they had been introduced to $14.3 \%$ of children in HCMC, $4.6 \%$ in Campbelltown and $4.4 \%$ in Singapore. By three years of age, they had been introduced to $47.6 \%$ of children in HCMC, $12.0 \%$ in Campbelltown and $15.4 \%$ in Singapore. These differences were statistically significant for both age and rate of introductions $p<0.05$. HCMC had introduced more CDs and at an earlier age than the other sites at a statisically significant rate to children ( $\leq 3$ years old). 
Period of exclusive breastfeeding by location

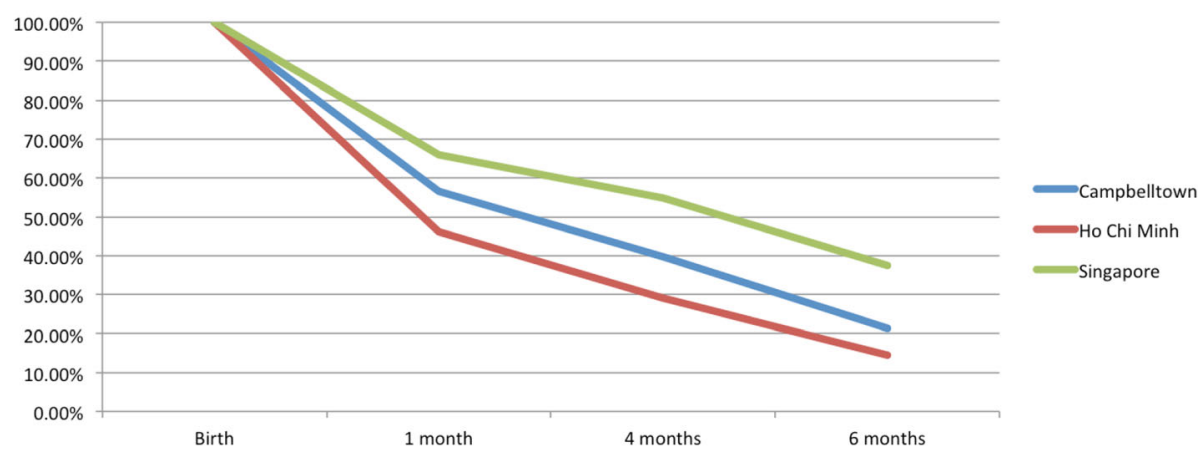

Fig. 1 Percentage of participants that were still exclusively breastfeeding by location

Table 1 shows the percentages of various drinks introduced to children (less than six years) in the three sites revealing high rates of consumption of drinks with elevated calorie and caffeine content in all areas. The rates were significantly increased in Vietnam for all types of drinks except $100 \%$ fruit juice.

Flavoured milk (Fig. 5) was introduced by the age of six months by participants at $4.8 \%$ in $\mathrm{HCMC}, 0.9 \%$ in Campbelltown, and $1.1 \%$ in Singapore. At one year, $22.6 \%$ of participants in HCMC had been introduced flavoured milk, compared to $7.4 \%$ in Campbelltown and $5.5 \%$ in Singapore. By three years of age, $41.7 \%$ of participants in HCMC had received flavoured milk, compared to $36.1 \%$ in Campbelltown and $24.2 \%$ in Singapore (Table 1). These differences were statistically significant by rate of introductions $p<0.05$, but not by age of introduction. HCMC had introduced more flavoured milk than the other sites at a statistically significant rate to children ( $\leq 3$ years old) but there was no significant difference between the sites at the age of initial introduction.

$100 \%$ fruit juice (Fig. 6) was introduced by $13.1 \%$ of participants in HCMC by the age of six months, compared with 7.4\% in Campbelltown and 8.8\% in Singapore. At one year, $44.1 \%$ of participants in HCMC had been introduced $100 \%$ fruit juice, compared to $21.3 \%$ in Campbelltown and $26.4 \%$ in Singapore. By three years of age, $50 \%$ of participants in Campbelltown and HCMC had been introduced 100\% fruit juice, compared to 38.5\% in Singapore (Table 1). These differences were not statistically significant by rate of introductions but by age of introduction $p<0.05$. HCMC had introduced 100\% fruit juice at an earlier age than the other sites at a statistically significant rate to children ( $\leq 3$ years old) but there was no significant difference between the sites for the number of introductions.

Fruit drink (Fig. 7) was introduced by $22.6 \%$ of participants in HCMC by six months, compared with $6.5 \%$ in Campbelltown and $4.4 \%$ in Singapore. By one year, 59.5\% of participants in HCMC had been introduced fruit drinks, compared to $20.4 \%$ in Campbelltown and $15.4 \%$ in Singapore. By three years, the rate rose to $72.6 \%$ of in HCMC, $40.7 \%$ in Campbelltown and 26.4\% in Singapore (Table 1 ). These differences were statistically significant by both rate and age of introductions $p<0.05$.

Non-caffeinated soft-drinks (Fig. 8) were introduced by $2.4 \%$ of participants in HCMC by six months, but none were introduced in Campbelltown and Singapore.

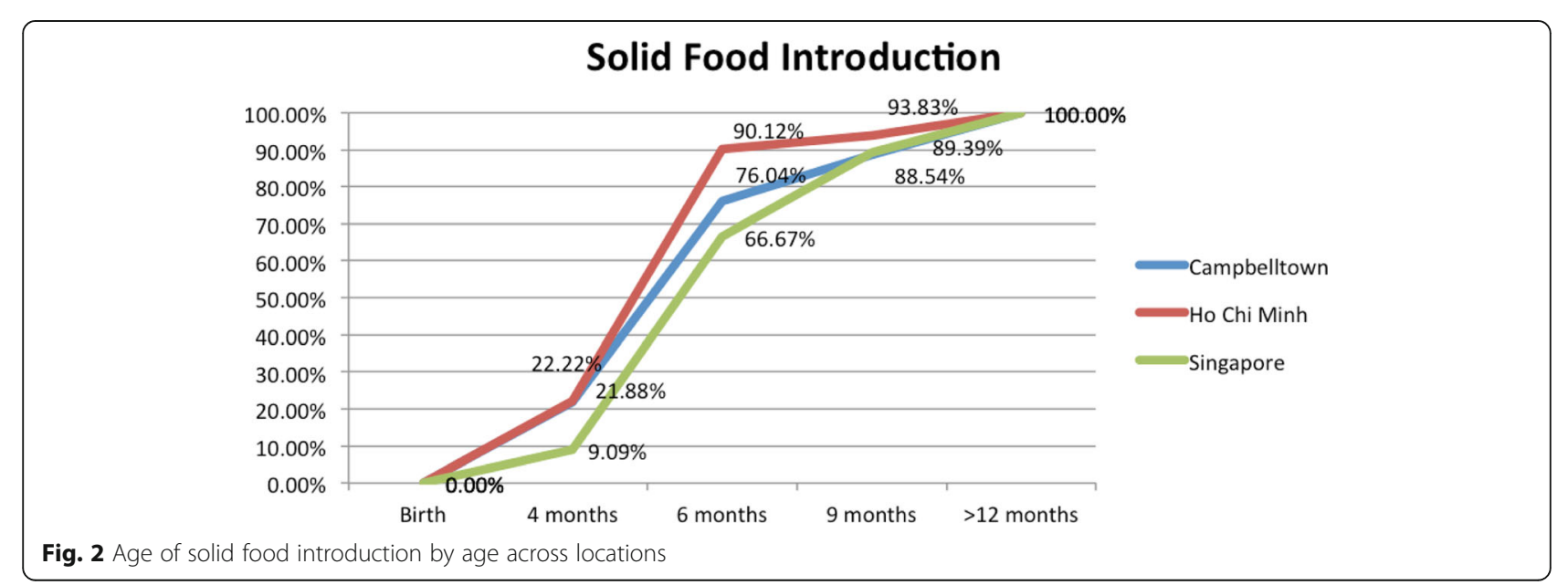




\section{High Caloric Drink Introduction}

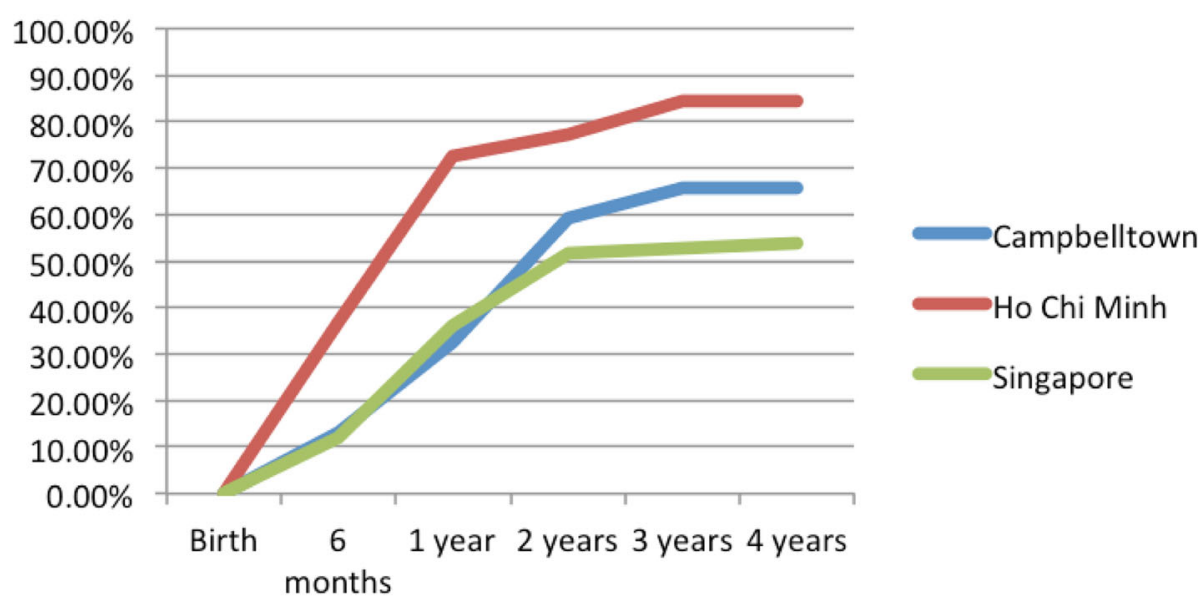

Fig. 3 Number of participants who introduced any high calorie beverage by age across locations

At one year, the rate rose to $11.9 \%$ of participants in HCMC, compared to $1.9 \%$ in Campbelltown and $5.5 \%$ in Singapore. By three years, $44.1 \%$ of participants in HCMC had been introduced non-caffeinated soft-drinks, compared to $18.5 \%$ in Campbelltown and $12.1 \%$ in Singapore (Table 1). The differences between the locations were statistically significant by the rate of introductions $p<0.05$, but not by the age of introduction.

Caffeinated soft-drinks (Fig. 9) were introduced by six months by $3.6 \%$ of participants in HCMC, but by none in Campbelltown and Singapore. By one year, $9.5 \%$ of participants in HCMC had introduced caffeinated soft drinks, compared to $0.9 \%$ in Campbelltown, and $1.1 \%$ in Singapore. By three years, the rate rose to $36.9 \%$ in
HCMC, 7.4\% in Campbelltown and 8.8\% in Singapore (Table 1). The differences between the locations were statistically significant by the rate of introductions $p<0.05$, but not by the age of introduction.

HCMC had the highest percentage of participants who had received CDs at an early age: (Fig. 11) by six months, $1.2 \%$; by one year $2.4 \%$, and by three years 10.7\% (Table 1).

Coffee (Fig. 11) was introduced by $1.2 \%$ of participants in HCMC by six months, but by none in Campbelltown and Singapore. At one year, the rate had risen to $7.1 \%$ of participants in HCMC, $1.9 \%$ in Campbelltown, and 2.2\% in Singapore. By three years, the rate had risen to $17.9 \%$ in $\mathrm{HCM}$ and to $3.3 \%$ in Singapore but was stable at $1.9 \%$

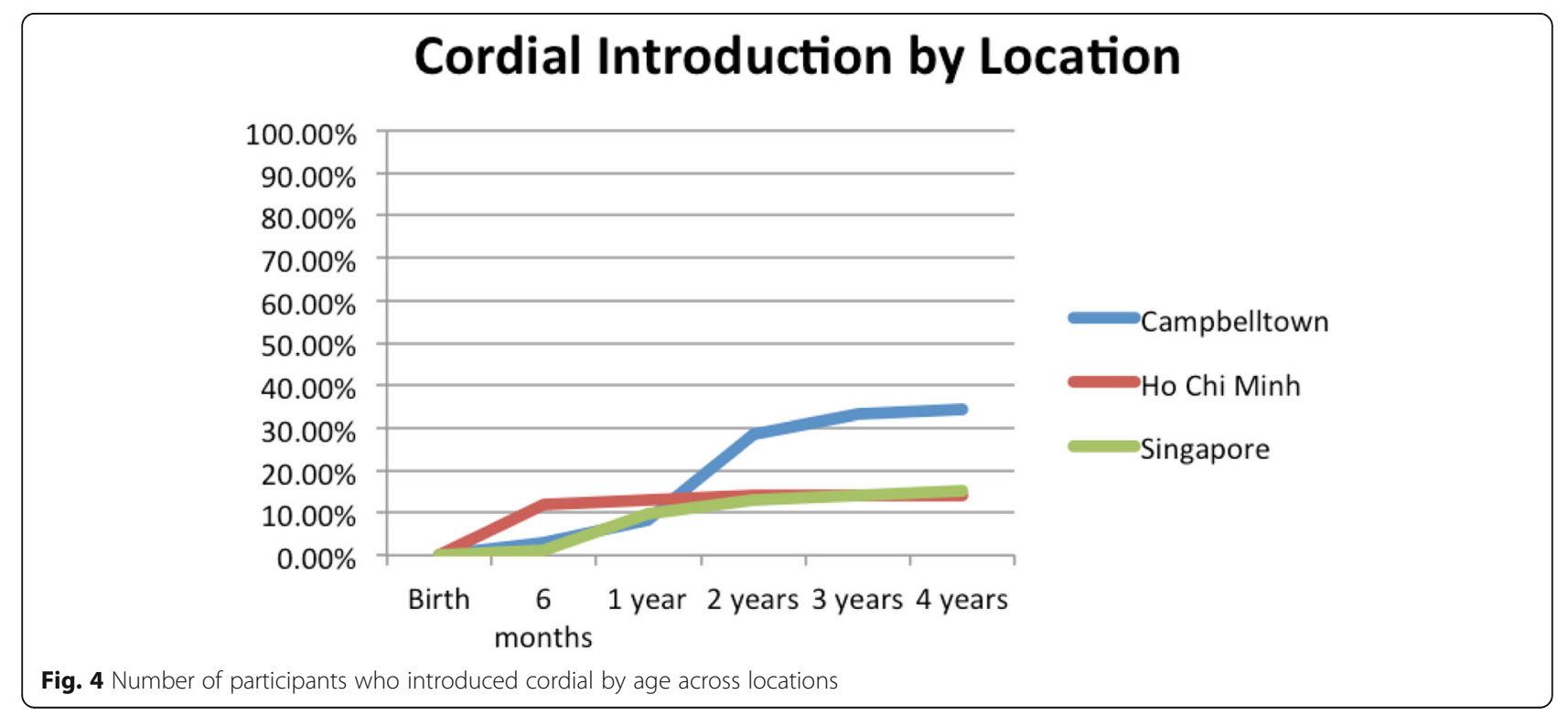




\section{Flavoured Milk Introduction by Location}

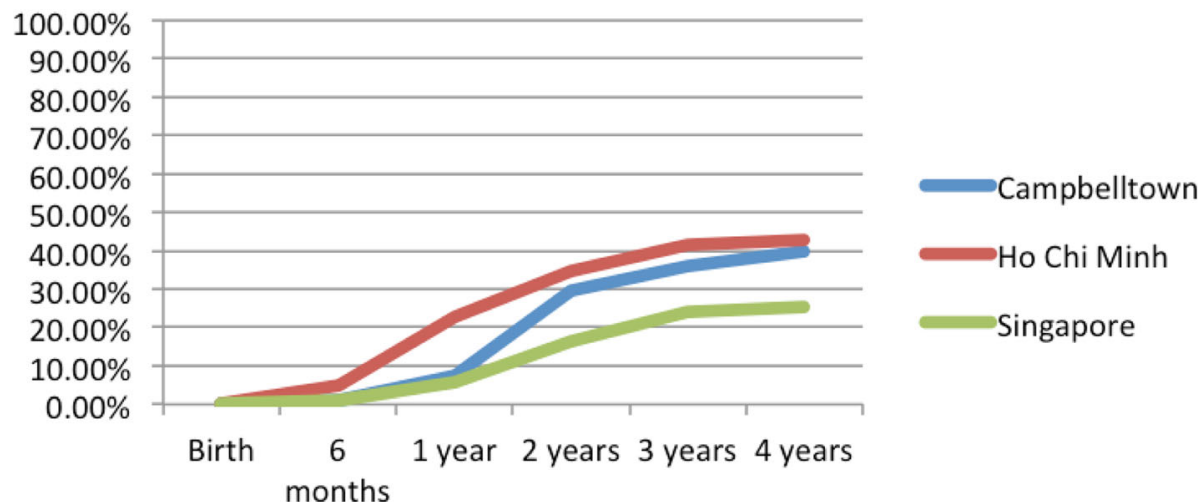

Fig. 5 Number of participants who introduced flavoured milk by age across locations

in Campbelltown (Table 1). These differences were statistically significant by the rate of introductions $p<0.05$, but not by the age of introduction.

Tea (Fig. 12) was introduced by six months in $4.8 \%$ of participants in HCMC, $0.9 \%$ in Campbelltown, and 1.1\% in Singapore. By one year the rate had risen to $10.7 \%$ of participants in HCMC, 3.7\% in Campbelltown, and 4.4\% in Singapore. By three years, it had risen to $16.7 \%$ in HCMC, $6.5 \%$ in Campbelltown and 5.5\% in Singapore (Table 1). These differences were statistically significant by rate of introductions $p<0.05$, but not by the age of introduction.

A significant association between the age of introduction of the following drinks (Table 2$)$ : water $(p<0.005)$, cordial $(p<0.005), 100 \%$ fruit juice $(p<0.05)$, and fruit drink $(p<0.005)$. Post-hoc Tukey HSD analyses showed that HCMC introduced water earlier than Campbelltown $(p<0.01)$, and Singapore $(p<0.00)$. HCMC also introduced cordial earlier than both Campbelltown $(p<0.00)$, and Singapore $(p<0.00) .100 \%$ fruit juice was introduced earlier in HCMC compared to Campbelltown $(p<0.04)$ and fruit drink was introduced earlier in HCMC compared to Campbelltown $(p<0.00)$. There was no statistical difference in the time of introduction of infant formula, cow's milk, flavoured milk, non-caffeinated soft drinks, caffeinated soft drinks, coffee, tea and solid foods between the different locations. Infant formula, non-caffeinated soft drinks, and caffeinated soft drinks were being introduced within months of birth (by 6 months). Only in Vietnam were high energy drinks being introduced to

\section{$100 \%$ Fruit Juice Introduction by Location}

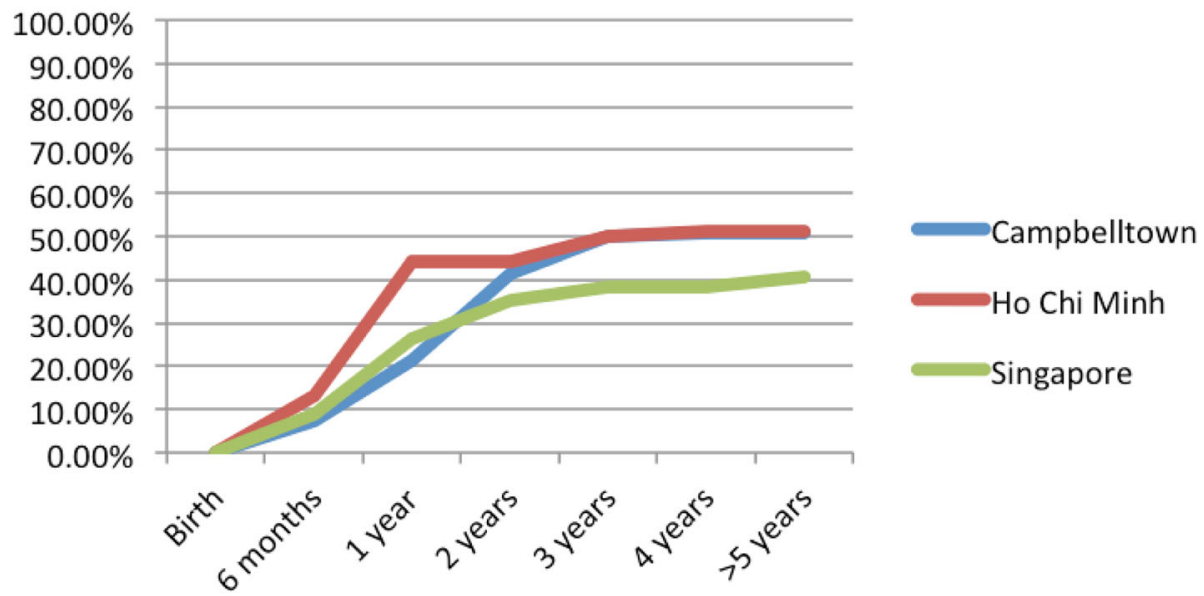

Fig. 6 Number of participants who introduced 100\% fruit juice by age across locations 


\section{Fruit Drink Introduction by Location}

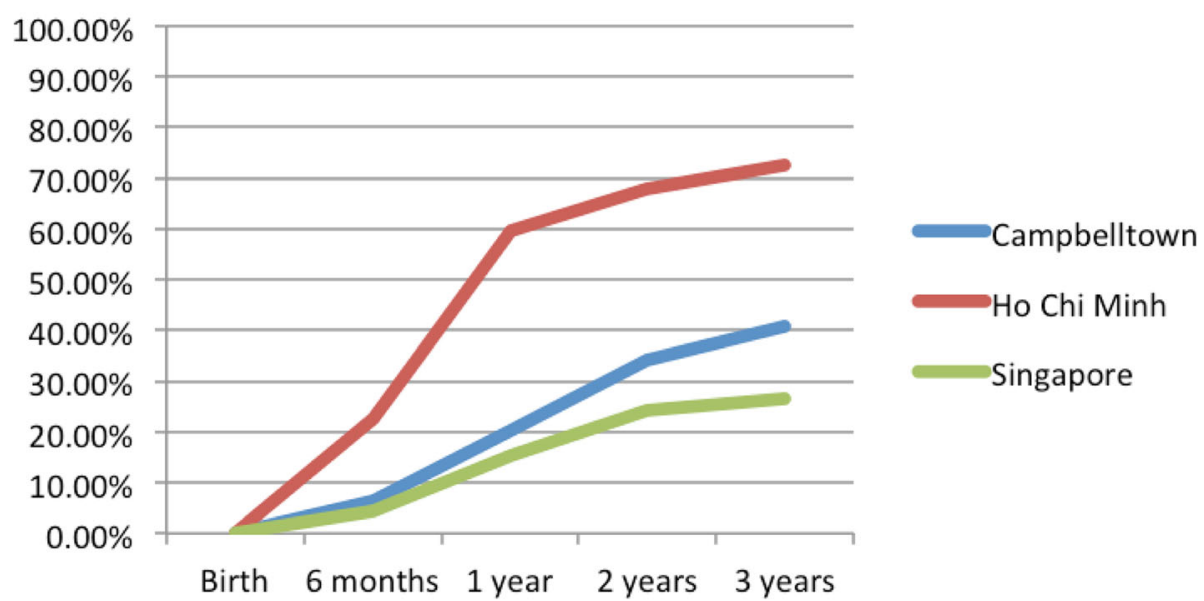

Fig. 7 Number of participants who introduced fruit drink by age across locations

children by 6 years of age. 9 respondents introduced energy drinks from $\mathrm{HCMC}$ but none from the other locations.

Significant differences in parent education levels were demonstrated $\mathrm{F}(2280)=15.40, p<0.00)$. Tertiary education was completed by $46.4 \%(n=39)$ in HCMC compared to $75.0 \%(n=81)$ in Campbelltown and $75.8 \%(n=69)$ in Singapore. $36.9 \%(n=31)$ of respondents in HCMC did not complete secondary school.

\section{Discussion}

The study revealed differences in feeding patterns between the sites. First, though breast feeding rates were lower in all areas than recommended by WHO $(24.72 \%)$, the rates were significantly lower in Vietnam (14.47\%). Second, overall rates of introduction to high caloric beverages were high, but particularly in Vietnam. Third, overall rates of introduction of caffeinated drinks were high (Avg: 17.58\% by two years of age) especially in HCMC.

Vietnam's 'Alive and Thrive' organisation seeks to increase breast feeding in that country and suggests several reasons for its low rate. First, is the popular misconception that Vietnamese women produce insufficient quantity and quality of breast milk. Second, is the practice of giving water after breastfeeding to clean the child's mouth and reduce lingering thirst, with the subsequent effect of

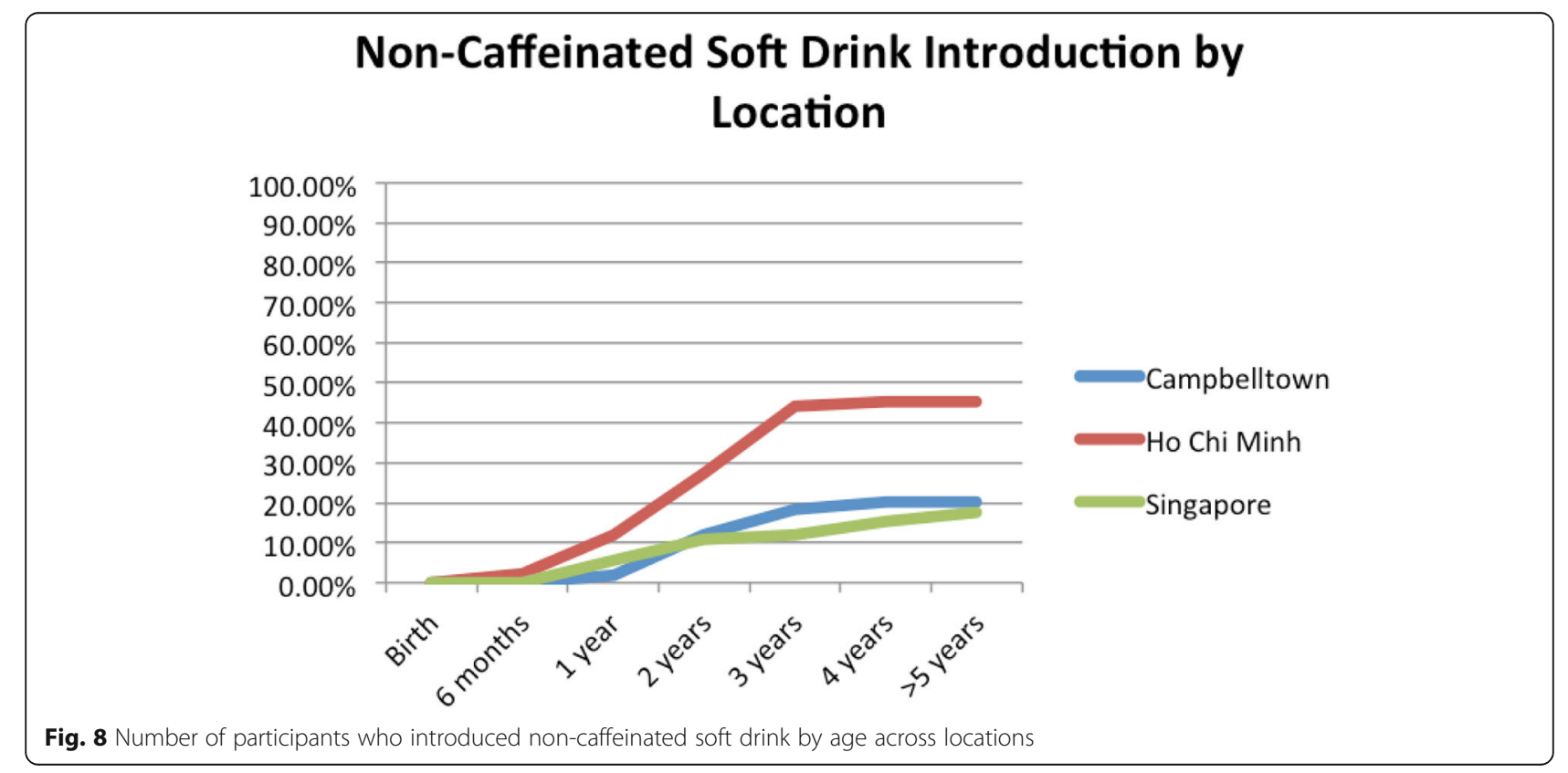




\section{Caffeinated Soft Drink Introduction by Location}

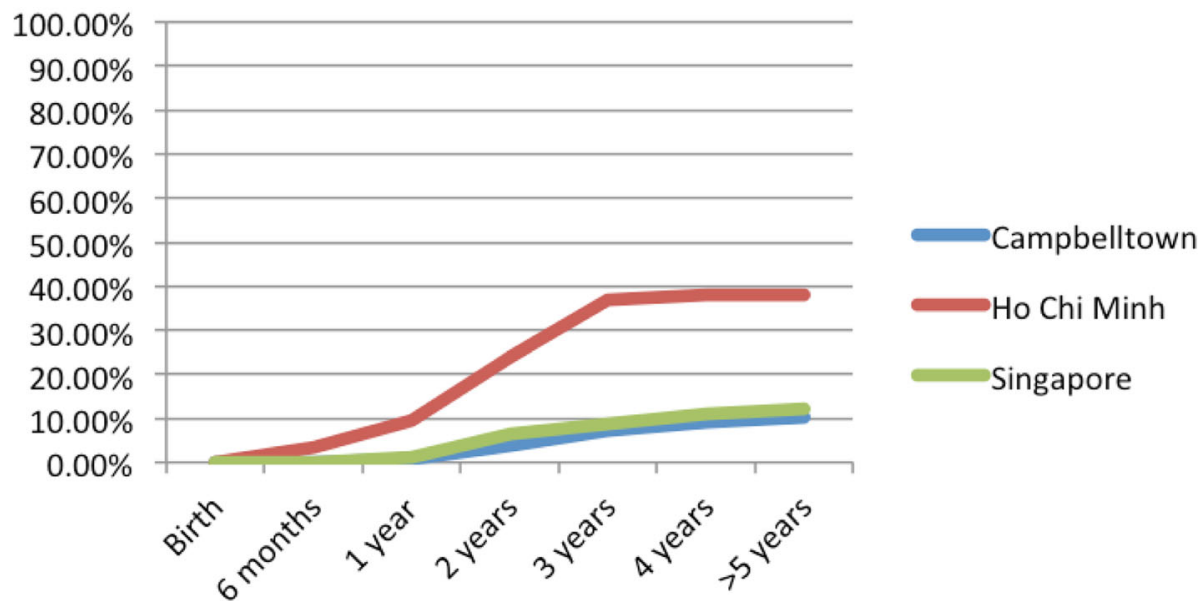

Fig. 9 Number of participants who introduced caffeinated soft drink by age across locations

reduced stimulation for milk production. Third, is the short official maternity leave of less than 4 months. Fourth, the aggressive marketing of infant formula. Fifth, the paucity of adequately trained breast feeding educators [48]. Lower levels of education are associated with lower rates of breast feeding and this association was confirmed in our study.

Efforts were introduced in 2010 to counter these obstacles to breast feeding and included extension of maternity leave to 6 months, banning advertising of alternatives to breastmilk, and introduction of lactation support programs in 70 locations, but rates have shown little improvement $[49,50]$.
HCMC's lower compliance with infant feeding guidelines is consistent with the lower rate of public health spending in Vietnam which, per year, is only $\$ 3.45$ per capita, compared to Australia's $\$ 41.70$ and Singapore's $\$ 56.90[46,47,51,52]$. This low rate of spending on health promotion in Vietnam contrasts with high rates of investment by infant formula companies. From 2010 to 2013, an estimated USD \$13 million was spent on advertising on infant formulas to secure a revenue of $\$ 1.23$ billion [53, 54].

Supplementation of breast feeding with infant formula was initiated earlier in Campbelltown where 37\% of respondents declared supplementation had been introduced

\section{Energy Drink Introuction by Location}

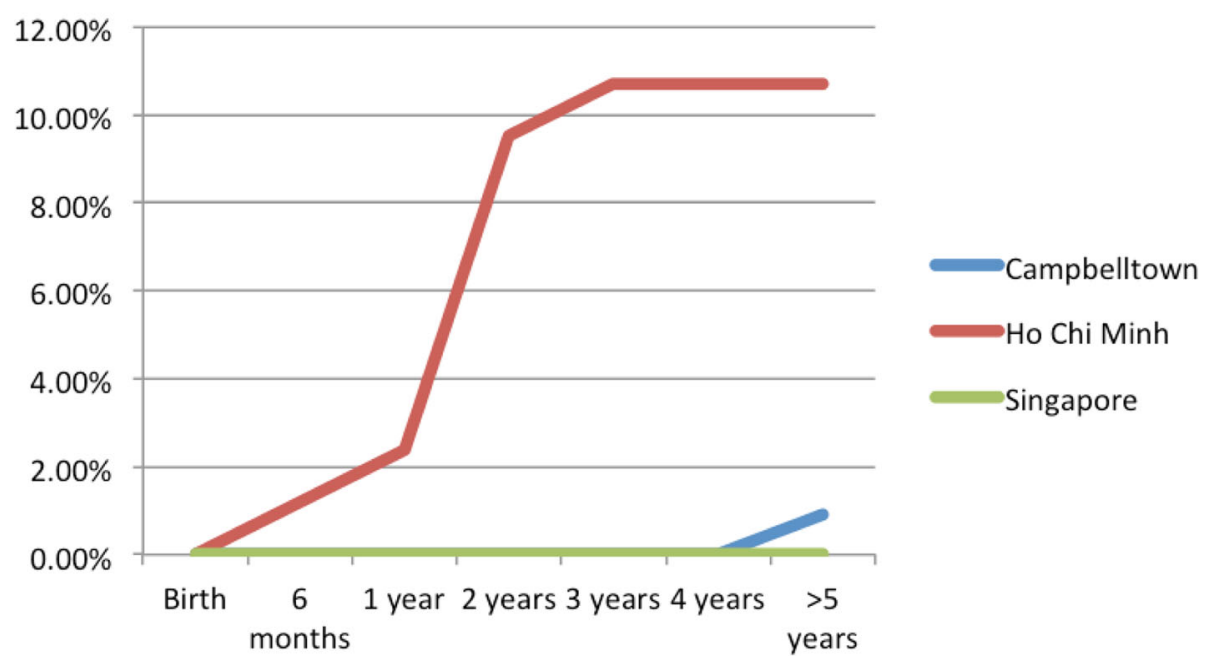

Fig. 10 Number of participants who introduced energy drinks by age across locations 


\section{Coffee Introduction by Location}

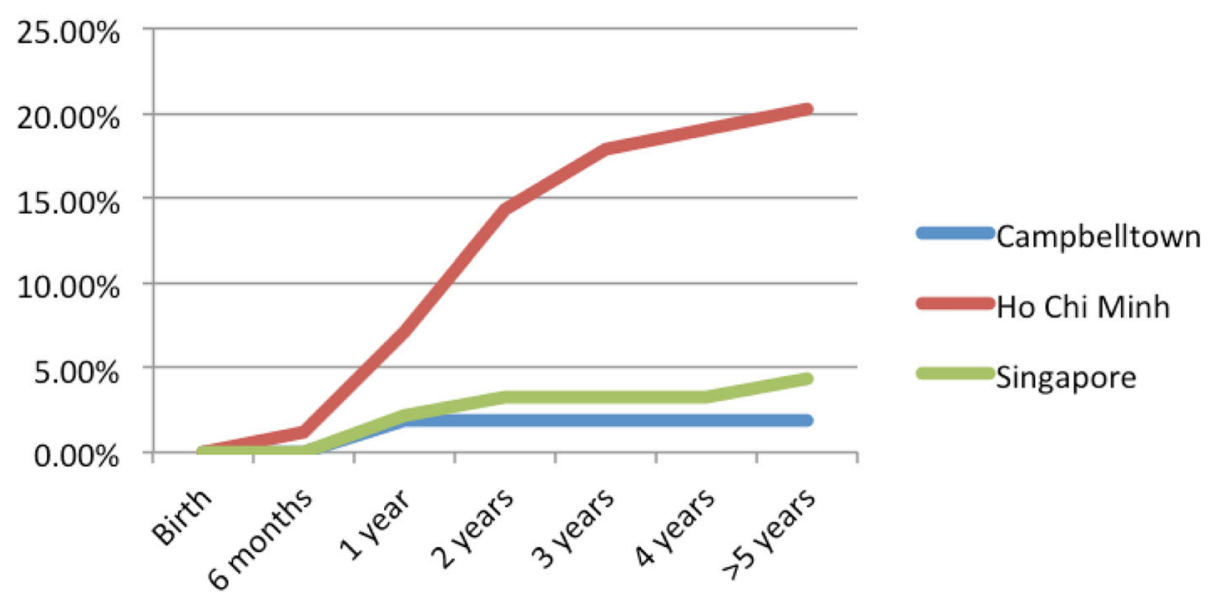

Fig. 11 Number of participants who introduced coffee by age across locations

at birth, compared with $26 \%$ in HCMC and $24 \%$ in Singapore. As infant formula is reported to be associated with development of obesity, this early introduction in Campbelltown may contribute to the higher rate of childhood obesity in that site (25\% compared to 16.5 in HCMC and $11 \%$ in Singapore) [34-39, 55].

High calorie drinks were introduced earlier in Vietnam than in the other sites, coinciding with investment by their manufacturers. The most popular STING energy drink company is reported to have invested US\$250 million from 2010 to 2013 [56], and Coca Cola announced a new US\$300 million investment in 2012, increasing its total to US $\$ 500$ million in the years 2010-2015 [57]. These companies are reported to have generated revenue of US\$56 million and US\$113 million respectively in 2010 [56, 57].

High calorie drinks are promoted as being healthy but provide little else than carbohydrate. Merely one serving provides $480-675 \mathrm{~kJ}[58,59]$, or $15 \%$ of the recommended daily energy requirements, thus contributing to obesity [22, 60-62]. Also the volume consumed competes with consumption of proteins, vitamins and minerals $[18,22]$. Parents may be misled by false advertising that these juices are 'healthy' and need government protection [63].

Caffeine is a psychoactive stimulant, reported to contribute to hyperactivity [21, 64], addictive behaviours [30], and depression [65]. According to Goldman [21] caffeinated

\section{Tea Introduction by Location}

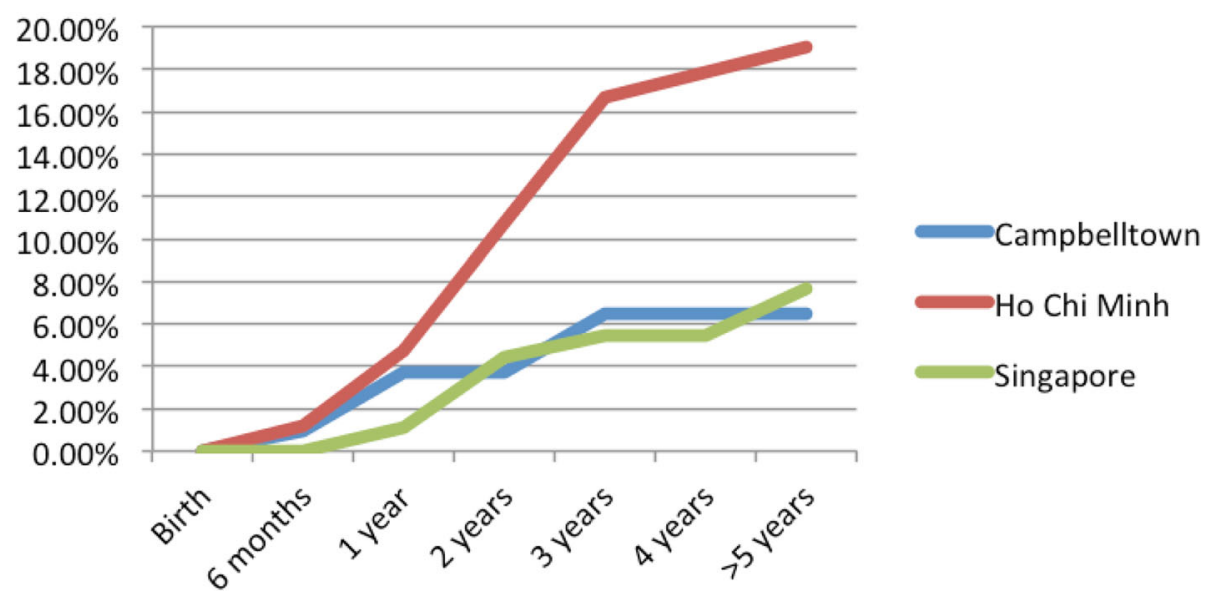

Fig. 12 Number of participants who introduced tea by age across locations 


\section{Caffeinated Drink Introduction}

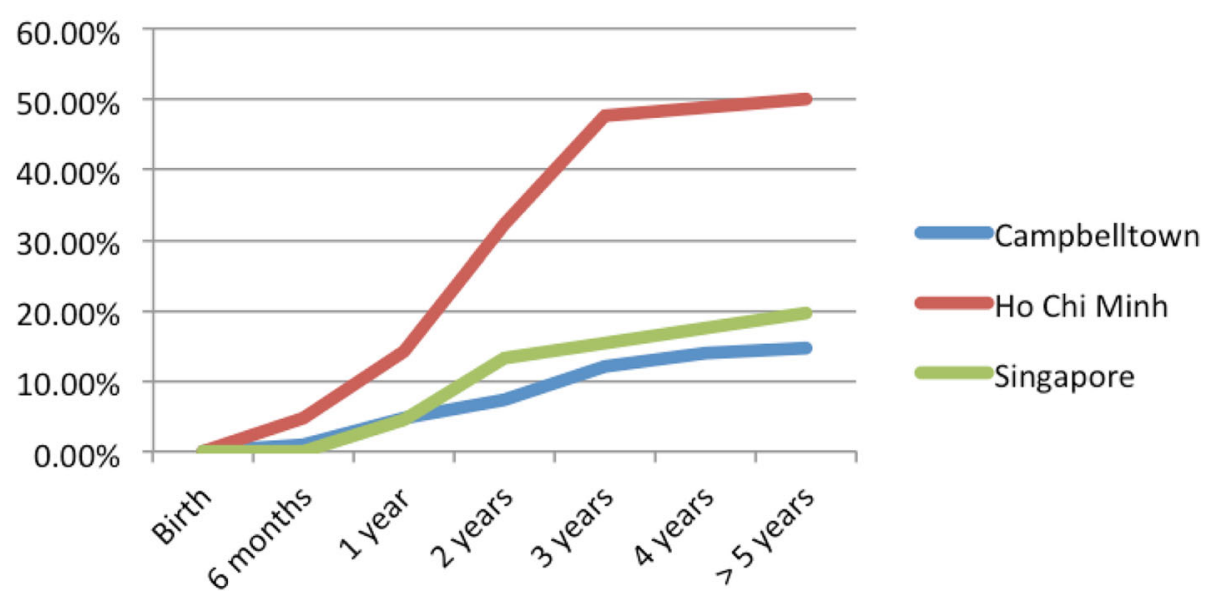

Fig. 13 Number of participants who introduced any caffeinated drink by age across locations

energy drinks are not recommended to children, due to its potential harmful effects. While Temple [30] and Beckford [66] highlight rising concerns with the introduction of caffeinated beverages to children and the need for further research into toxicity. Caffeine was introduced in all sites, but earlier and to many more children in Vietnam, in coffee, energy drinks and tea.

Our study has shown differences in rates of breast feeding between the sites, and that the differences correlate with introduction and consumption of high calorie feeds, all of which are known to correlate with obesity $[5,16,67]$. While rates of obesity have increased in recent years in all sites, the rates are higher in Vietnam in association with reduced breast feeding and increased caloric consumption in infancy [55, 68-70]. In Vietnam, overall, obesity rates increased in children, from $3.2 \%$ to $6.3 \%$ between 2002 and 2005 [55, 71]. In HCMC, in
2010, the rate of overweight/obese adolescents was $21 \%$ [55]. However, in Vietnam we note that urban regions experience a much greater increase in rates of obesity as compared to the suburban/rural areas [38, 55, 72, 73]. In Australia, the rate of overweight children has increased from $21 \%$ in 1995 to $25.7 \%$ in $2011-12$ [37, 68]. In Singapore, child obesity rates remained steady at $12 \%$ between 2010 and 2013 [74].

Limitations to the study included its limited sample size due to allocated time frame of data collection, the possible feeling of intimidation of respondents by a supervised questionnaire in cultures not familiar with total freedom of expression, and the lack of direct measurement of obesity rates amongst the child participants. The fact the questionnaires were distributed near government health facilities may have increased this intimidation as well as selection bias.

Table 1 Rates of introduction of various drinks (ages 0-6 years old) according to location

\begin{tabular}{lllll}
\hline & Ho Chi Minh City, $n=84(\%)$ & Campbelltown, $n=108(\%)$ & Singapore, $n=91(\%)$ & Total, $n=283(\%)$ \\
\hline Water & $83(98.8 \%)$ & $96(88 . \%)$ & $77(84.6 \%)$ & $256(90.5 \%)$ \\
Cow's milk & $23(27.4 \%)$ & $70(64.8 \%)$ & $28(31.1 \%)$ & $125(44.2 \%)$ \\
Cordial & $12(14.2 \%)$ & $37(34.3 \%)$ & $14(15.4 \%)$ & $63(22.2 \%)$ \\
Flavoured milk & $36(42.9 \%)$ & $43(39.8 \%)$ & $23(25.3 \%)$ & $102(36.0 \%)$ \\
$100 \%$ Fruit juice & $43(51.2 \%)$ & $55(50.9 \%)$ & $36(29.6 \%)$ & $134(47.3 \%)$ \\
Fruit Drink & $61(72.6 \%)$ & $44(40.7 \%)$ & $24(26.4 \%)$ & $129(45.6 \%)$ \\
Non-caffeinated soft-drink & $38(45.2 \%)$ & $22(20.4 \%)$ & $15(16.5 \%)$ & $75(26.5 \%)$ \\
Caffeinated soft-drink & $32(38.1 \%)$ & $10(9.3 \%)$ & $11(12.1 \%)$ & $53(18.7 \%)$ \\
Energy drinks & $10(12.0 \%)$ & $1(0.9 \%)$ & 0 & $11(3.9 \%)$ \\
Coffee & $17(20.2 \%)$ & $2(1.9 \%)$ & $4(4.4 \%)$ & $23(8.1 \%)$ \\
Tea & $16(19.0 \%)$ & $7(6.5 \%)$ & $7(7.7 \%)$ & $30(10.6 \%)$ \\
\hline
\end{tabular}


Table 2 One-way analysis of variance (ANOVA) between locations for the age of introduction of drinks

\begin{tabular}{llllll}
\hline & Sum of squares & df & Mean square & $F$ & $p$ \\
\hline Water & 3.562 & 2 & 1.781 & 7.321 & 2.549 \\
Cow's milk & 4.503 & 2 & 2.252 & 18.339 & 0.001 \\
Cordial & 37.843 & 2 & 18.921 & 1.774 & 0.000 \\
Flavoured milk & 4.501 & 2 & 2.250 & 3.120 & 0.175 \\
100\% Fruit juice & 8.566 & 2 & 4.283 & 6.563 \\
Fruit Drink & 12.635 & 2 & 6.317 & 0.326 & 0.047 \\
Non-caffeinated soft-drink & 0.843 & 2 & 0.422 & 1.411 & 0.723 \\
Caffeinated soft-drink & 3.983 & 2 & 1.991 & 0.269 \\
Coffee & 1.214 & 2 & 0.607 & 0.253 \\
Tea & 5.181 & 2 & 2.590 & 0.767 \\
\hline
\end{tabular}

\section{Future research}

HCMC's poorer compliance with WHO infant feeding recommendations is of concern. Continuing research on factors that influence infant feeding practices is basic to the development of appropriate interventions in all three sites to reduce subsequent rates of obesity and its complications.

\section{Conclusions}

There was statistical significance between the duration of exclusive breastfeeding, the age of introduction of cordial, flavoured milk and fruit drink between the regions, as well as the educational level of respondents. Vietnam had lower rates of breast feeding but higher rates of introduction of $\mathrm{HCBs}$ and $\mathrm{CDs}$, which were associated with lower rates of education achievement. These feeding practices are reflected in rising obesity rates and the need for greater programs of education and perhaps government interventions to favour breast feeding and restrict false advertising of HCBs and CDs.

\section{Additional files}

Additional file 1: The infant feeding survey. (DOCX $51 \mathrm{~kb}$ )

Additional file 2: Descriptive statistics of the carer/parent. (DOCX $17 \mathrm{~kb}$ )

Additional file 3: Descriptive statistics of the child. (DOCX 16 kb)

\section{Abbreviations}

CB: Caffeinated beverages; HCB: High calorie beverages; HCMC: Ho Chi Minh City, Vietnam; NGO: Non-governmental organisation; SWS: Campbelltown (South Western Sydney), New South Wales, Australia; USD: United States of America dollar

\section{Acknowledgements}

We would like to acknowledge A/Prof. Daisy Chan, Dr. Vina 'Joy' C Tagamolila, from Singapore General Hospital for their guidance, advice, and support throughout the research process. Dr. Phan Nguyen for his support in Vietnam. Cheryl Ong and Jae Ric Teh for their aid in producing the initial questionnaire. Diane Premnath and Michelle $\mathrm{Ng}$ for their assistance in proof-reading.

\section{Funding}

None.

\section{Availability of data and materials}

The datasets during and/or analysed during the current study are included in this article.

\section{Authors' contributions}

$\mathrm{TL}$ conception and design, acquisition, analysis, and interpretation of data, drafting and revising of manuscript; $A U$ conception and design, acquisition, analysis, and interpretation of data, draft of manuscript; SQ conception and design, acquisition and interpretation of data, draft and revising of manuscript; JN conception and design, acquisition of data, draft of manuscript; YA conception and design, acquisition of data, draft of manuscript; PM obtaining ethics approval, analysis and interpretation of data, revising of manuscript; JW conception and design, acquisition, analysis and interpretation of data, drafting and revising of manuscript. All authors read and approved the final manuscript.

\section{Competing interests}

The authors declare that they have no competing interests.

\section{Consent for publication}

Not applicable.

\section{Ethics approval and consent to participate}

Ethics approval was obtained from the University of Western Sydney Human Research Ethics Committee (HREC H9140, H9067), Liverpool Local Health District for the site at Campbelltown Hospital (HREC/13/LPOOL/153 and SSA) 13/LPOOL/154), Singapore General Hospital (CIRB 2015/2078), and Xom Moi Medical Centre certification. Implied consent was obtained through completion of the questionnaire.

\section{Publisher's Note}

Springer Nature remains neutral with regard to jurisdictional claims in published maps and institutional affiliations.

Received: 21 November 2016 Accepted: 7 June 2017

Published online: 13 June 2017

\section{References}

1. Shenkin JD, Heller KE, Warren JJ, Marshall TA. Soft drink consumption and caries risk in children and adolescents. Gen Dent. 2003;511:30-6.

2. McCann MF, Baydar N, Williams RL. Consumption of soft drinks and other sweet drinks by WIC infants. Am J Public Health. 2008;98:1735.

3. Libuda L, Alexy U, Remer T, Stehle P, Schoenau E, Kersting M. Association between long-term consumption of soft drinks and variables of bone modeling and remodeling in a sample of healthy German children and adolescents. Am J Clin Nutr. 2008;886:1670-7.

4. Weinberger $\mathrm{MH}$. Are children doomed by what they eat and drink? Hypertension. 2008;51:615-6. 
5. James J, Kerr D. Prevention of childhood obesity by reducing soft drinks. Int J Obes. 2005;29:S54-7.

6. Seach KA, Dharmage SC, Lowe AJ, Dixon JB. Delayed introduction of solid feeding reduces child overweight and obesity at 10 years. Int J Obes. 2010; 34:1475-9.

7. Arora A, Scott JA, Bhole S, Do L, Schwarz E, Blinkhorn AS. Early childhood feeding practices and dental caries in preschool children: a multi-centre birth cohort study. BMC Public Health. 2011;11:28.

8. Dhingra R, Sullivan L, Jacques PF, Wang TJ, Fox CS, Meigs JB, et al. Soft drink consumption and risk of developing cardiometabolic risk factors and the metabolic syndrome in middle-aged adults in the community. Circulation. 2007;116:480-8.

9. WHO: Fact sheet N ${ }^{\circ} 342$ : Infant and young child feeding. Media Centre. World Health Organisation; 2016.

10. WHO: Global strategy for infant and young child feeding. UNICEF. Geneva: World Health Organization; 2001.

11. NHMRC. Australian Dietary Guidelines. Commonwealth of Australia: Council National Health and Medical Research Council, Canberra; 2013.

12. ASCIA. Infant feeding and allergy prevention. ASCIA guidelines. Australasian Society of Clinical Immunology and Allergy: NSW; 2016.

13. Infant and young child health and nutrition booklet. In: The Little Sun: Health and Nutrition booklet. Haâ Nöåi: Alive \& Thrive Vietnam; 2014.

14. HPB: Healthy start for your baby. Health Promotion Board. Singapore: Healthier Child, Brighter Future initiative; 2015.

15. NHMRC. Infant Feeding Guidelines. Commonweath of Australia: National Health and Medical Research Council, Canberra; 2012.

16. Yan J, Liu L, Zhu Y, Huang G, Wang PP. The association between breastfeeding and childhood obesity: a meta-analysis. BMC Public Health. 2014:14:1-11.

17. WHO: Exclusive breastfeeding to reduce risk of childhood overweight and obesity - biological, behavioural and contextual rationale. e-Library of Evidence for Nutrition Actions (eLENA). Geneva: WHO; 2014.

18. Hester SN, Hustead DS, Mackey AD, Singhal A, Marriage BJ. Is the macronutrient intake of formula-fed infants greater than breast-fed infants in early infancy? J Nutr Metab. 2012;2012:891201.

19. Imai CM, Gunnarsdottir I, Thorisdottir B, Halldorsson TI, Thorsdottir I. Associations between infant feeding practice prior to six months and body mass index at six years of age. Nutrients. 2014;6:1608-17.

20. Sidnell $A$, Greenstreet E. Infant nutrition - protein and its influence on growth rate. Nutr Bull. 2009;34:395-400.

21. Goldman RD. Caffeinated energy drinks in children. Can Family Phys. 2013;59:947-8.

22. Vartanian $L R$, Schwartz MB, Brownell KD. Effects of soft drink consumption on nutrition and health: a systematic review and meta-analysis. Am J Pub Health. 2007:97:667-75.

23. Malik VS, Pan A, Willett WC, Hu FB. Sugar-sweetened beverages and weight gain in children and adults: a systematic review and meta-analysis. Am J Cli Nutr. 2013;98:1084-102.

24. Pan L, Li R, Park S, Galuska DA, Sherry B, Freedman DS. A Longitudinal Analysis of Sugar-Sweetened Beverage Intake in Infancy and Obesity at 6 Years. Pediatrics. 2014;134(Supplement 1):S29-S35.

25. Pan W-H, Yeh W-T, Weng L-C. Epidemiology of metabolic syndrome in Asia. Asia Pac J Clin Nutr. 2008;17:37-42.

26. Park S, Pan L, Sherry B, Li R. The association of sugar-sweetened beverage intake during infancy with sugar-sweetened beverage intake at 6 years of age. Pediatrics. 2014;134:S56-62.

27. WHO: Guideline: Sugars intake for adults and children. Geneva: World Health Organization. 2015;49.

28. Reissig CJ, Strain EC, Griffiths RR. Caffeinated energy drinks - a growing problem. Drug Alcohol Depend. 2009;99:1-10.

29. MacDonald N, Stanbrook M, Hébert PC. "caffeinating" children and youth. Can Med Assoc J 2010;182:1597-97.

30. Temple JL. Caffeine use in children: what we know, what we have left to learn, and why we should worry. Neurosci Biobehav Rev. 2009;33:793-806.

31. WHO: Fact sheet N ${ }^{\circ} 311$ : Obesity and overweight. Media Centre. World Health Organisation; 2015.

32. Singh AS, Mulder C, Twisk JW, van Mechelen W, Chinapaw MJ. Tracking of childhood overweight into adulthood: a systematic review of the literature. Obe Rev. 2008;9:474-88.

33. Liang Y, Hou D, Zhao X, Wang L, Hu Y, Liu J, et al. Childhood obesity affects adult metabolic syndrome and diabetes. Endocrine. 2015;50:87-92.
34. Loke KY, Lin JB, Mabel DY. 3rd college of paediatrics and child health lecture-the past, the present and the shape of things to come. Ann Acad Med Singap. 2008;37:429-34.

35. Koon OT. Obesity and health promotion amongst students. Singapore: Ministry for Education - Parliamentary Replies; 2012.

36. ABS: Gender indicators, Australia, Jan 2013 (4125.0). In., 30/01/2013 edn. Canberra: Australian Bureau of Statistics; 2013.

37. ABS: Children who are overweight or obese. Australian Bureau of Statistics, Canberra; 2009.

38. Thi Thu Dieu H, Dibley MJ, Sibbritt D, Thi Minh Hanh T. Prevalence of overweight and obesity in preschool children and associated sociodemographic factors in Ho Chi Minh City, Vietnam. International J Ped Obes. 2007: 2:40-50.

39. Childhood nutrition: community-school and hospital approaches [in Vietnamese]. Open Nutrition Conference. Ho Chi Minh City Nutrtion Center: TRUNG TÂM DINH DƯ NG; 2014.

40. de Onis M, Blossner M, Borghi E. Global prevalence and trends of overweight and obesity among preschool children. Am J Clin Nutr. 2010;92:1257-64.

41. Wang Y, Lobstein T. Worldwide trends in childhood overweight and obesity. Int J Pediatr Obes. 2006;1:11-25.

42. UNICEF. Improving child nutrition: the achievable imperative for global progress. UNICEF. New York: United Nations Children's Fund; 2013.

43. Hartley R. Families and cultural diversity in Australia. Allen \& Unwin and Australian Institute of Family Studies - Commonwealth of Australia; 1995

44. Wise S. Silva Ld. Differential parenting of children from diverse cultural backgrounds attending child care. Commonwealth of Australia: Australian Institute of Family Studies, Canberra; 2007.

45. SWSLHD: Operational Plan 2014-2018. Department of health. Sydney: Population Health - South Western Sydney Local Health District; 2014.

46. CIA: The World Factbook: Singapore 2016-17. Central Intelligence Agency, Washington, DC; 2016.

47. CIA: The World Factbook: Vietnam 2016-17. Central Intelligence Agency, Washington, DC; 2016.

48. Nguyen PH, Manohar S, Mai LT, Subandoro A, Rawat R, Menon P. Alive \& Thrive Baseline Survey Report: Viet Nam. In: Washington D.C.: Alive \& Thrive; 2011.

49. Iellamo A: Joint programme on integrated nutrition and food security strategies for children and vulnerable groups in Viet Nam (MDG-F 2010-2013). United Nations MDG Achievement Fund; 2013.

50. Nguyen PH, Menon P, Ruel M, Hajeebhoy N. A situational review of infant and young child feeding practices and interventions in Viet Nam. Asia Pac J Clin Nutr. 2011;20:359-74.

51. Health expenditure, public (\% of total health expenditure). The World Bank Data. Washington D.C.: The World Bank Group; 2015.

52. CIA: The World Factbook: Australia 2016-17. Central Intelligence Agency. Washington, DC; 2016.

53. Giang NH, Hajeebhoy N. Nguyen T. Talking Babies Media Campaign. Social and Behaviour Change Communication Spotlights. Health COMpass: Alive \& Thrive Viet Nam; 2015

54. Stocking B, Hong VT. AP: baby formula illegally marketed abroad. CBS Interactive: CBS News/Associated Press. New York; 2009.

55. Nguyen PVN, Hong TK, Hoang T, Nguyen DT, Robert AR. High prevalence of overweight among adolescents in ho chi Minh City. Vietnam BMC Public Health. 2013:13:1-7.

56. Stones M. PepsiCo invests $\$ 250 \mathrm{~m}$ in Vietnam. Foodnavigator-asiacom. William Reed Business Media: Montpellier; 2010.

57. Ngoc HB, Ngoc HQ, Thuy HTT, Trang NT. Coca Cola Vietnam's marketing plan. In: academia - business plans \& marketing strategy. San Francisco: Academia.edu; 2016.

58. VMC: Calorie Counter. In.: Virtual Medical Centre; 2014

59. Coca-Cola. In: Coca-Cola Journey. The Coca-Cola Company; 2016.

60. NHMRC. Dietary energy. National Health and Medical Research Council. NHMRC: Australia; 2006.

61. Cai X, Wardlaw T, Brown D. Global trends in exclusive breastfeeding. Int Breastfeed J. 2012;7:12.

62. Hauck Y, Fenwick J, Dhaliwal S, Butt J. A Western Australian survey of breastfeeding initiation, prevalence and early cessation patterns. Matern Child Health J. 2011;15:260-8.

63. American Academy of Pediatrics. The use and misuse of fruit juice in pediatrics. Pediatrics. 2001;107:1210-3.

64. Castellanos FX, Rapoport JL. Effects of caffeine on development and behavior in infancy and childhood: a review of the published literature. Food Chem Toxicol. 2002;40:1235-42. 
65. Benko CR, Farias AC, Farias LG, Pereira EF, Louzada FM, Cordeiro ML. Potential link between caffeine consumption and pediatric depression: a case-control study. BMC Pediatr. 2011;11:73.

66. Beckford K, Grimes CA, Riddell $\sqcup$. Australian children's consumption of caffeinated, formulated beverages: a cross-sectional analysis. BMC Public Health. 2015;15:70.

67. Dehghan M, Akhtar-Danesh N, Merchant AT. Childhood obesity, prevalence and prevention. Nutr J. 2005:4:1-8.

68. ABS: National Health Survey: First Results, 2014-15 (4364.0.55.001). In., 08/12/2015 edn. Canberra: Australian Bureau of Statistics; 2015.

69. Soon G. Koh YH. Lam PW. Obesity prevention and control efforts in Singapore. The National Bureau of Asian Research: Wong ML; 2008.

70. Li M, Dibley MJ. Child and adolescent obesity in Asia. In: A Modern Epidemic: Expert Perspectives on Obesity and Diabetes. Baur L, Twigg SM, Magnusson RS (eds), Sydney University Press; 2012.

71. Hong TK, Dibley MJ, Sibbritt D, Binh PN, Trang NH, Hanh TT. Overweight and obesity are rapidly emerging among adolescents in ho chi Minh City, Vietnam, 2002-2004. Int J Pediatr Obes. 2007;2:194-201.

72. Walls HL. Peeters a, son PT, Quang NN, Hoai NT, Loi do D, Viet NL, Khai PG, Reid CM. Prevalence of underweight, overweight and obesity in urban Hanoi, Vietnam. Asia Pac J Clin Nutr. 2009;18:234-9.

73. Do LM, Tran TK, Eriksson B, Petzold M, Nguyen CTK, Ascher H. Preschool overweight and obesity in urban and rural Vietnam: differences in prevalence and associated factors. Global Health Action 2015, 8:10.3402 gha.v3408.28615

74. MINDEF. Obesity in children. Ministry of Defence Singapore: MINDEF; 2013.

\section{Submit your next manuscript to BioMed Central and we will help you at every step:}

- We accept pre-submission inquiries

- Our selector tool helps you to find the most relevant journal

- We provide round the clock customer support

- Convenient online submission

- Thorough peer review

- Inclusion in PubMed and all major indexing services

- Maximum visibility for your research

Submit your manuscript at www.biomedcentral.com/submit

C) Biomed Central 